\title{
Community Engagement: Where Reality Meets the Road*
}

\author{
Emilie Joy Kistnasamy \\ Durban University of Technology, Durban, South Africa
}

\begin{abstract}
Community engagement is an important higher education pillar which underlies a meeting of the theoretical as taught at universities, with the practical as it occurs in the real world. Learning in this holistic manner allows primary customers of universities: the students, to professionally and confidently anticipate the real world. They are empowered to understand the dynamics of working with excellence in solving issues and contributing to society, in a meaningful, respectful, timely, organized, and feasible manner. This paper will firstly, discuss five community engagement projects that final year Environmental Health students participated in, in Durban, South Africa. This will be followed by a discussion on the key components of community engagement projects that should be considered such as project planning, collaboration practices, overcoming challenges, celebrating successes and evaluation. These components are based on my experience in managing these community engagement projects from conception to conclusion.
\end{abstract}

Keywords: South Africa, higher education, environmental health, community engagement projects, project components

\section{Introduction}

Institutions of higher learning worldwide are constantly revising and re-focusing on why they exist. Key to this thinking is to find mechanisms that can make positive contributions to the well-being of society and address environmental problems at the community level (Clifford \& Petrescu, 2012), develop innovative ways to integrate research, instruction, and outreach (Tanaka \& Mooney, 2010) and enhance informed practice and strengthen community capacity (Clay, Sagrestano, \& Finerman, 2012). In South Africa, higher education institutions are endeavouring to work collaboratively with industry, government and community partners (Brown-Luthango, 2013) in order to achieve the above objectives.

Engagement is the partnership of university knowledge and resources with those of the public and private sectors to enrich scholarship, research, and creative activity; enhance curriculum, teaching, and learning and prepare educated, engaged citizens, strengthen democratic values and civic responsibility; address societal issues; and contributes to the public good. (Committee of Institutional Cooperation Committee on Engagement, 2005, as cited by McNall, Reed, Brown, \& Allen, 2009)

It is therefore vital that this component of higher education be given priority as its output has ripple effects, not only on the student's education but also, on their emotional, social, and professional advancement and their future adult development.

\footnotetext{
*Acknowledgements: The author acknowledges the expert advice, quality input, financial/logistical support and proactive thinking of all collaborators and students that so ably and enthusiastically participated in these projects.

Emilie Joy Kistnasamy, Lecturer, Department of Community Health Studies, Faculty of Health Sciences, Durban University of Technology.
} 
The greatest learning experience is to do and understand. Here, the student takes full responsibility to assimilate, plan, co-ordinate, network, and develop novel approaches for knowledge dissemination and integrate these experiences gained, into his or her worldview (Magwood et al., 2012; Pike, Kuh, \& McCormick, 2011; Zhao \& Kuh, 2004). Therefore, the primary goal of community engagement activities is to benefit the place of higher education by bringing forth new knowledge and improving the teaching and learning process (Bernardo, Butcher, \& Howard, 2012). Community engagement allows for scholarship, research and creative ability to be enriched. Curriculum development, teaching, and learning is enhanced and an educated and engaged citizen is prepared for the real world. Hopefully this "peep" into reality will help the student to knowledgeably contribute to strengthening democratic values in the future so that societal issues can be addressed and this overall, adds value to public good.

To this end and as a lecturer, the author has endeavoured to undertake an annual community engagement project with her students so that they can take note that Environmental Health is a key foundation in Public Health and has strong humanistic and social justice components (Howard, Rao, \& Desmond, 2010). For the purposes of this paper, only five community engagement projects will be discussed. A discussion will then follow on the author's experiences in planning community engagement projects, collaboration, overcoming project challenges, celebrating successes, and evaluating project outcomes.

\section{Community Engagement Projects}

\section{Project 1: World Environment Day Roadshow (2013) (see Figures 1 and 2)}

The 5th June 2013 was World Environmental Day with the theme: THINK-EAT-SAVE. In collaboration with a local Oil Refinery, students hosted an environmental sustainable awareness roadshow to six primary schools in Durban, South Africa. Students were randomly allocated to a group and then as a group, to one of the six schools. The hour long program consisted of several activities inclusive of a play, a presentation on the effects of misuse of natural resources and on control measures that the children could implement in their own lives. The children answered questions based on the presentations and received gifts for answering correctly and for participating. The school Principal was then presented with a certificate of acknowledgment for the schools' participation in this roadshow.

\section{Project 2: Medical Waste Audit (2009)}

This collaborative project with groundWork (a South African non-profit environmental justice service and developmental organisation) sought to conduct a cradle-to-grave audit of the medical waste generated in three public hospitals in Durban, South Africa. The randomisation process was again followed to allocate students to groups and to each hospital. To begin the process, each group undertook literature reviews and developed survey tool(s) to conduct these forthcoming audits. The tool(s) needed to consider the following: (1) South African and International legislation used in medical waste management; (2) A profile of the generated medical waste; and (3) The handling, treatment, transportation, and disposal of the generated medical waste. These tool(s) were then reviewed by all concerned and one audit tool was finalised for use in the three hospitals. On completion of the audit, comprehensive reports inclusive of findings and feasible recommendations were compiled, orally presented and electronic copies given to collaborators including groundWork, infection control nurses, nursing managers and government officials. 


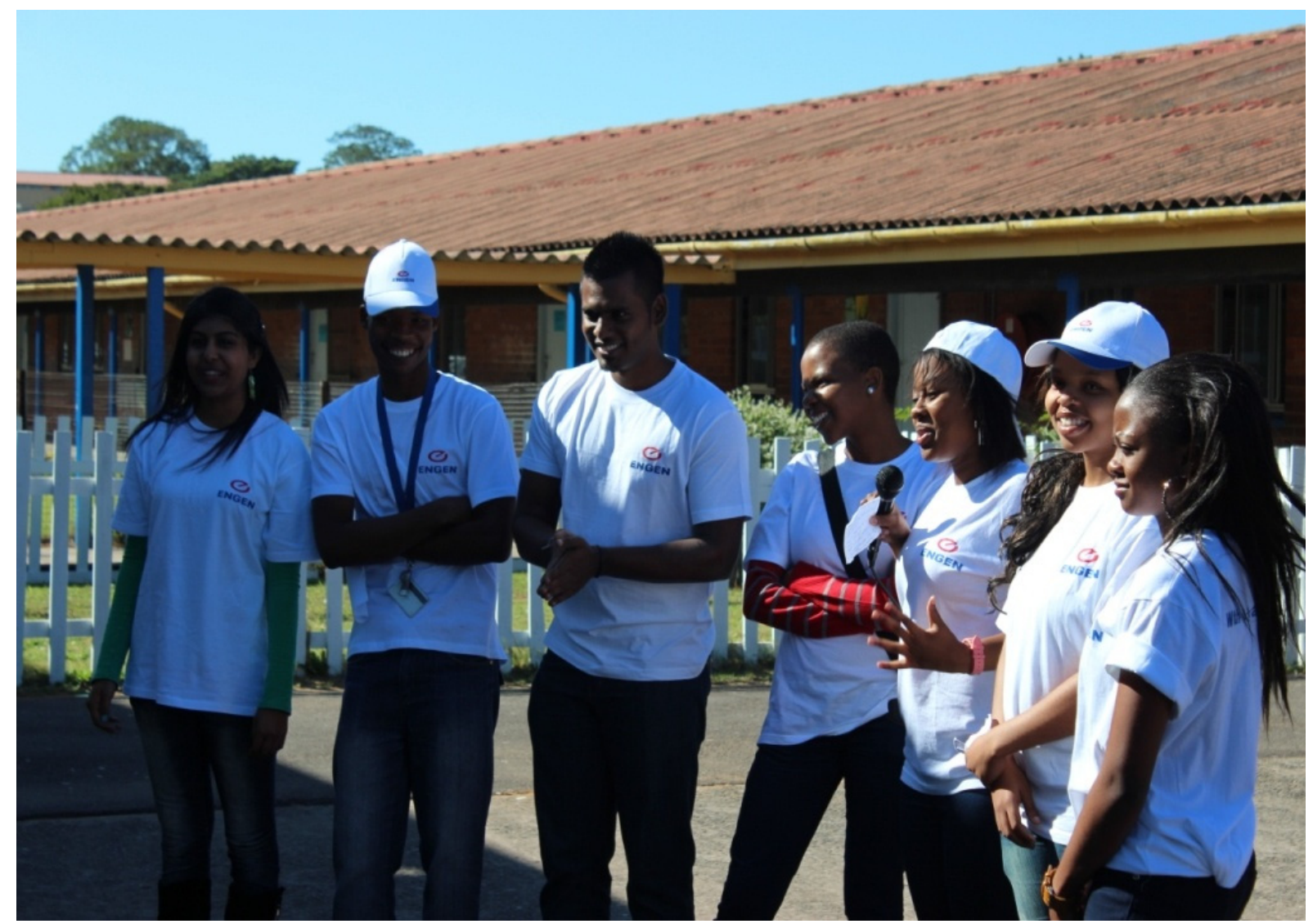

Figure 1. Environmental health students at one of the schools.

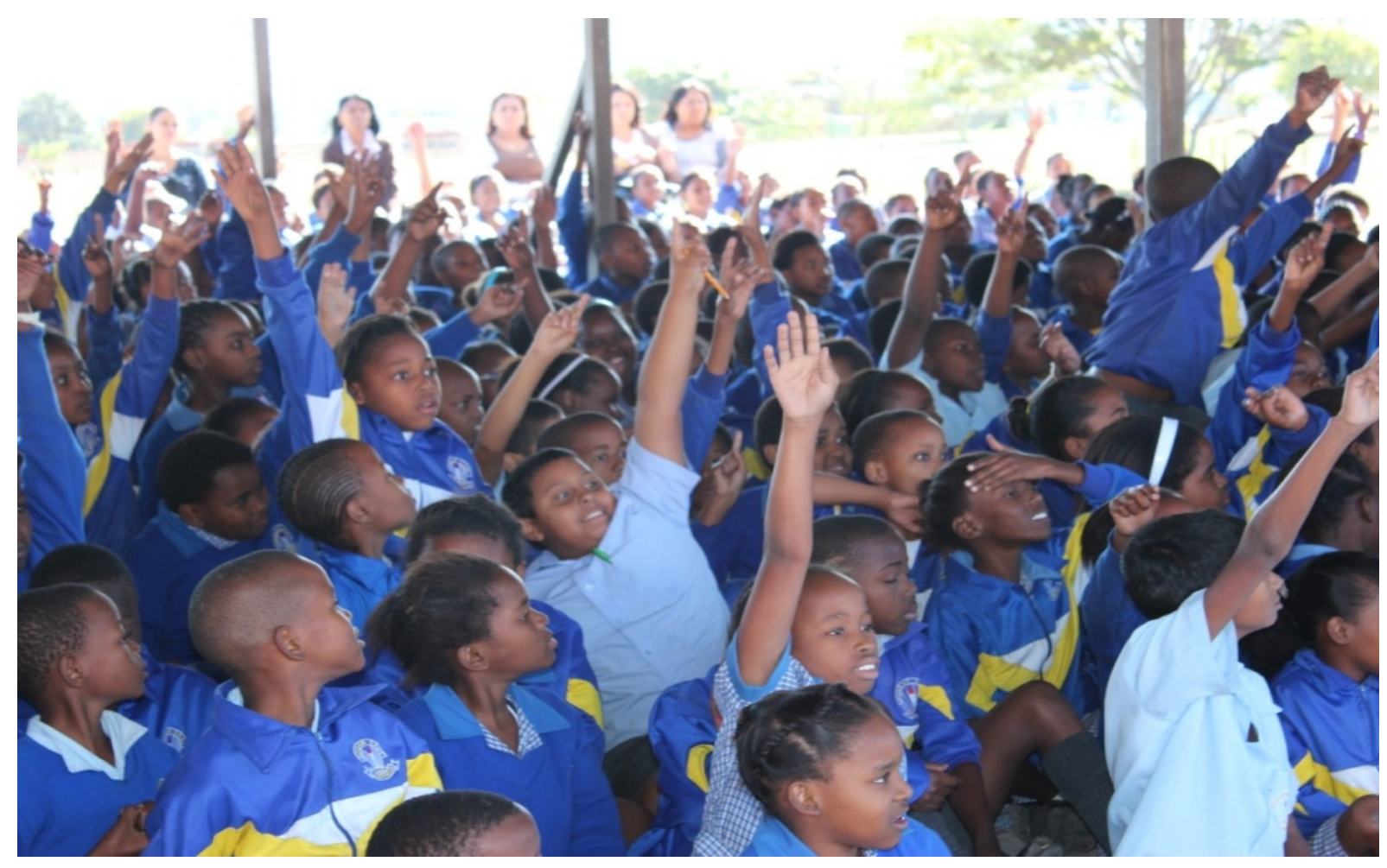

Figure 2. Primary school children participating in the Roadshow. 


\section{Project 3: Pollution Control Project (2008)}

This project was undertaken in collaboration with the Health unit of our local municipality, Durban, South Africa. Students were randomly allocated to groups and then to specific locations in the city. Each group elected a leader and was given a City Mentor, i.e., an Environmental Health Practitioner, to help further the project objectives. The project involved the following: (1) a photographic collage of the pollution problems at the chosen location; (2) designing and administering a questionnaire which included the following components: Knowledge, Attitudes, Practices, socio-economic issues and health status; (3) an analysis of results using a Logframe Approach (as this was used by the municipality); (4) based on the previous findings, develop a pamphlet which can be used by the municipality to educate and raise the level of awareness regarding the burning of waste materials; and (5) compile a list of all stakeholders with full contact details and inclusive of both the public and private sectors that can help make this process a success.

\section{Project 4: Materials Development Project (2006) (see Figures 3 and 4)}

This project was undertaken in collaboration with a public hospital whose main clientele consisted of poor people from the surrounding area. The key health issues that patients presented with included: tuberculosis, AIDS, cholera, diabetes, high blood pressure, violence/abuse, and heart attacks noting that chronic diseases affects health and human development with those groups at a social and economic disadvantage, far more likely to experience adverse outcomes (Fawcett, Schultz, Holt, \& Collie-Akers, 2013). The aim then was to develop various resource materials to improve and maximise hospital practices and help empower this disenfranchised community as regards the above diseases/issues.

After consultation with hospital management, consensus was reached that booklets and posters would be produced by students, in collaboration with the Department of Graphic Design students at the Durban University of Technology. These were disseminated to patients and staff and as advocated by the South African government, added value to our Batho Pele principles, i.e., consultation, service standards, access, courtesy, information, openness and transparency, redress and value for money. This form of collaboration also aided the Environmental Health learner develop new ideas and concepts by engaging in cross-sectoral collaboration. To thank the hospital for their collaboration efforts, the students renovated the four Paediatric Wards of the hospital and this today, still stands as a testament of their attitude of gratitude.

\section{Project 5: Compilation of a Health Education Manual for Primary Schools (2004)}

The South Durban Health Study (in which the author participated) explored the relationship between environmental exposures and health in Durban, South Africa (Naidoo et al., 2007). This was a collaborative study between two South African universities and the School of Public Health at the University of Michigan, USA. Grade 4 pupils from seven primary schools in Durban participated in this study.

As a goodwill gesture and in order to empower these schools regarding the key concepts researched in the above study, i.e., air pollution, allergens, asthma, cardiovascular disease, cancer, exposure to environmental lead, nutrition and tobacco smoking; a health education project was developed in conjunction with the primary investigators. The main aim of this project was to develop a user friendly health education manual for primary schools which could be used both as a teaching and library resource. It was envisaged that this project would assist the schools and the surrounding community and as advocated by Howard, Rao, and Desmond (2010) contribute as follows: (1) make a difference in civic life; (2) promote the quality of life; and (3) develop the necessary knowledge, values and skill sets to help facilitate healthy outcomes. 


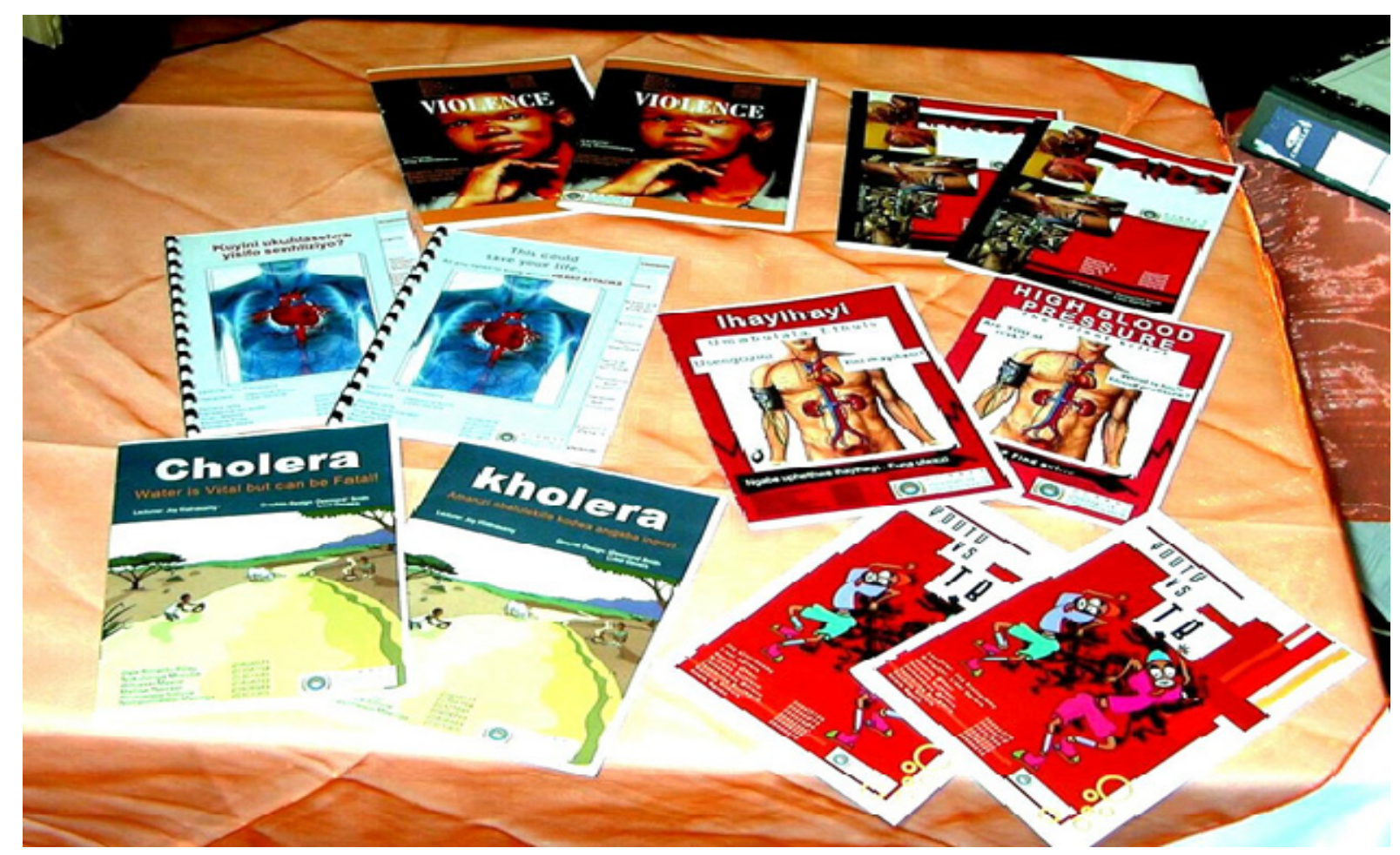

Figure 3. Booklets produced by students.

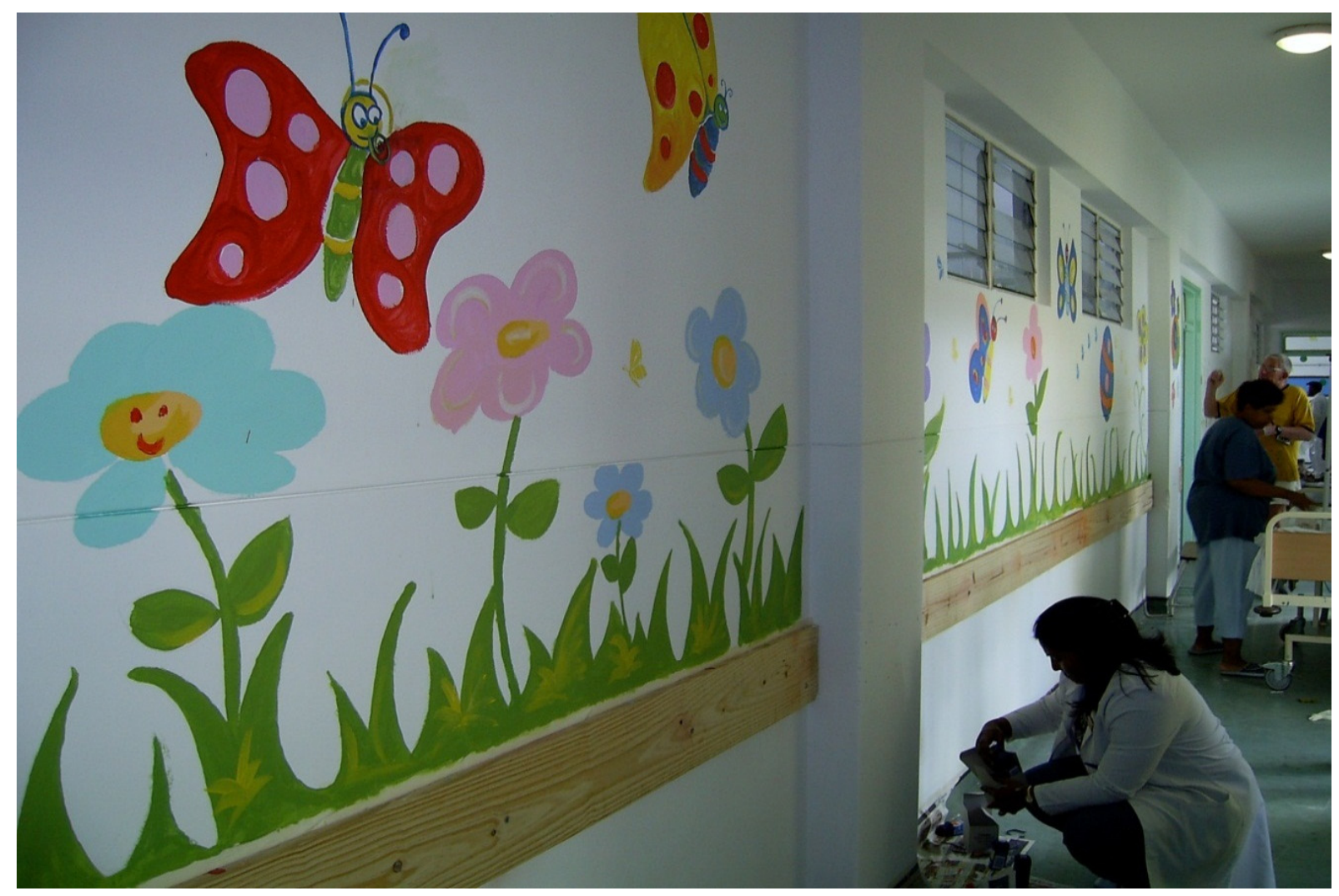

Figure 4(a). Renovating of the paediatric ward. 


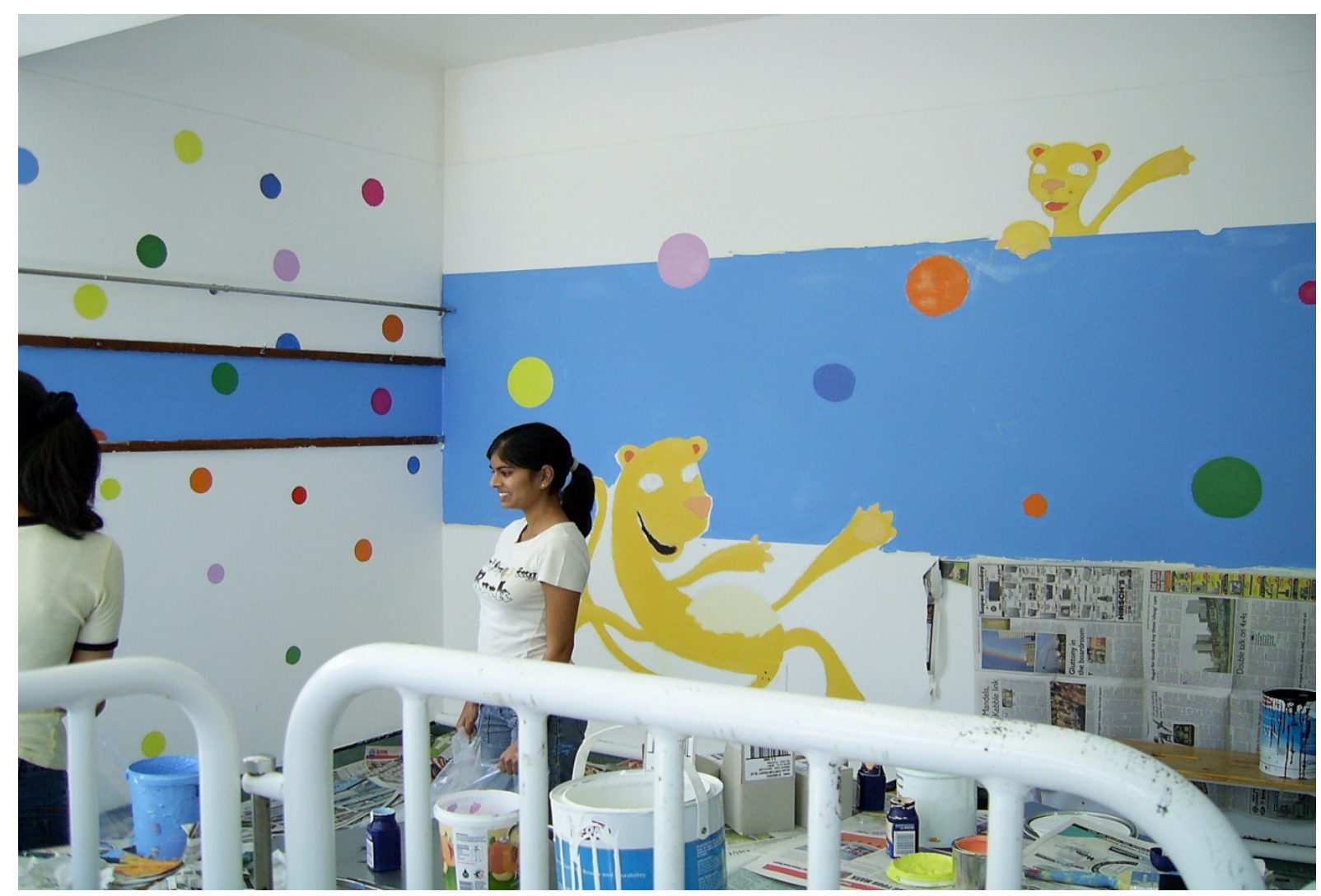

Figure 4(b). Renovating of the paediatric ward.

For this community project, students were randomly allocated into groups and one of the eight concepts was then randomly chosen by each group leader. Each concept needed to have the following information detailed: definition, causes/contributing factors, diagnosis and prevention and control techniques. Creative methods of expressing this information needed to be used in order to positively engage the manuals' main future users, i.e., primary schoolchildren.

\section{Key Concepts to Consider When Undertaking Community Engagement Project}

\section{Planning Community Engagement Projects}

There is always some problem to be solved. Having a curious mind, an empathetic heart and a passion to help, contributes greatly to initiating community engagement projects. Therefore, it is important to always ask, consult and network with all possible stakeholders be it community, industry, and government. Having a bull dog mentality of never giving up during the planning phase, contributes greatly to achieving future project outcomes, especially when it will be for the greater good and upliftment of society. When planning, it is vital to consider all aspects of the project from its inception till its conclusion and in some cases, even beyond the termination of the project. Having regular, focussed and timely meetings with all stakeholders during the planning phase helps diminish possible challenges that may arise during the implementation phase of the project.

\section{Managing Collaboration}

Initiating and managing collaboration requires that "Stakeholders should not be nave about the time, effort and investment which these kinds of engagements require and the difficulty of establishing, maintaining 
and sustaining genuine, mutually beneficial university-community collaborations" (Brown-Luthango, 2013), noting that universities have an obligation to engage with communities for the benefit of both (Jacelon, Donoghue, \& Breslin, 2010) and by aligning educational objectives with community partners' needs, community engagement projects are meant to also enhance reciprocal learning (Thomson, Smith-Tolken, Naidoo, \& Bringle, 2011).

To achieve the above goals, it is vital to get to know your stakeholders, their expectations and their knowledge base. Never ever underestimate their experiences and the value that they bring to the collaborative process and the project. It is important to earn respect and there should, as the project unfolds, be an unpacking of mutual respect. This can only occur when integrity exists as a core foundation of the collaboration process, i.e., when what one thinks, says and does all equals the same. Co-ordinated, user friendly, and constant feedback is crucial to achieving mutual respect. Areas of contention should always be discussed and resolved in a timely, mutually beneficial and proactive manner. Additionally, allowing the group leaders and the students to play a role in managing partnerships and collaboration efforts, inclusive of conflict resolution, allows them to develop attributes that will be empowering as a future professional and adult.

\section{Overcoming Project Challenges}

What may start of as a community project of note can turn into a problem of massive proportions, even though proper planning was done and collaboration processes managed effectively and efficiently. O'Brien (2009) noted that "On the ground, inequitable power relationships and erratic participation have posed serious challenges to the effectiveness and sustainability of engagement initiatives". Experience has shown to never let the project start if one does not have $100 \%$ stakeholder buy-in. Iron out all discrepancies, issues, allegations, and perceptions in a frank, timely and holistic manner without being overbearing or condescending. Endeavour at all times to maintain a spirit of excellence by being goal and solution oriented. This precedes aiming for perfection as it leaves room for growth and change. However, helping a community to sustain a project after the conclusion of a university-community engagement can be problematic. The sustainability aspect should therefore be discussed and accounted for in the planning stage of the project.

\section{Celebrating Project Successes}

To celebrate project successes, letters of acknowledgment, certificates of participation and media coverage (Mvelase, 2009) escalates the spirit of goodwill for all stakeholders. When students and collaborating partners' involvement is celebrated and highlighted in a fun and exciting way, it allows all stakeholders to value each aspect of a project and the functions and contributions of themselves and each other. Letters and certificates additionally help enhance curriculum vitae and gives the student an invaluable stepping stone into the job market and future job promotions.

A major goal of these projects though, is to engage the student in proactive thinking, understanding processes and become useful in the real world. The students' emotional understanding gives them an insider perspective into the situations and problems that require intervention in order to achieve a common goal (Singh, 2013) and eventually leads to an actively engaged citizen (Thomson et al., 2011). They become prepared to meet new challenges and work with others in interdisciplinary settings (Wallen \& Pandit, 2009). Bowman, Brandenberger, Lapsley, Hill, and Quaranto (2010) are also of the opinion that these types of university-community engagements contribute positively in adulthood including personal growth, purpose in life, environmental mastery and life satisfaction. 


\section{Evaluating Project Outcomes}

This last but important step is sometimes the most valuable tool in the toolkit of university-community engagements. It assists in evaluating from project inception to project conclusion and is not limited to: (1) the stakeholder involvement; (2) the stages of the project process; (3) the positives; (4) the challenges and the solutions; (5) the lessons learnt from the process; and (6) how these lessons can better inform the next project. In order for this process to be a success, it demands transparency, honesty, empathy and strategic thinking.

\section{Conclusion}

The author has endeavoured to use community engagement projects in order to not only fulfil the obligations of a lecturer whose work is underpinned by core pillars of higher education inclusive of teaching and learning; research and community engagement BUT to empower students to understand, realise and action their education in a fulfilling manner. Given the context of a developing country such as South Africa, it is empowering to note the pride on students' faces and in their posture when they realise that their education and engagement was used for a greater good in society and they may have contributed in uplifting those that were less knowledgeable, environmentally disempowered or socially disadvantaged. In the end, that's what community engagement is really all about!

\section{References}

Bernado, M. A. C., Butcher, J., \& Howard, P. (2012). An international comparison of community engagement in higher education. International Journal of Educational Development, 32, 187-192.

Bowman, N., Brandenberger, J., Lapsley, D., Hill, P., \& Quaranto, J. (2010). Serving in college, flourishing in adulthood: Does community engagement during the college years predict adult well-being? Applied Psychology: Health and Well-Being, 2(1), $14-34$.

Brown-Luthango, M. (2013). Community-university engagement: The Philippi CityLab in Cape Town and the challenge of collaboration across boundaries. High Educ., 65, 309-324.

Clay, J. A., Sagrestano, L. M., \& Finerman, R. (2012). Building relationships to strategically impact community initiatives to reduce teen pregnancy. JHHSA, Winter, 274-302.

Clifford, D., \& Petrescu, C. (2012). The keys to university-community engagement sustainability. Nonprofit Management \& Leadership, 23(1), 77-91.

Fawcett, S. B., Schultz, J. A., Holt, C. M., \& Collie-Akers, V. (2013). Participatory research and capacity building for community health and development. Journal of Prevention \& Intervention in the Community, 4, 139-141.

Howard, D., Rao C. R., \& Desmond, S. M. (2010). Borrowing from the east to strengthen the west: Merging public health case studies of community-based service-learning practices from India and the United States. Journal of Community Practice, 18, 336-360.

Jacelon, C. S., Donoghue, L. C., \& Breslin, E. (2010). Scholar in residence: An innovative application of the scholarship of engagement. Journal of Professional Nursing, 26(1), 61-66.

Magwood, G. S., Andrews, J. O., Zapka, J., Cox, M. J., Newman, S., \& Stuart, G. W. (2012). Institutionalization of community partnerships: The challenge for academic health centers. Journal of Health Care for the Poor and Underserved, 23, 1512-1526.

McNall, M., Reed, C. E., Brown, R., \& Allen, A. (2009). Brokering community. Innov. High Educ., 33, 317-331.

Mvelase, N. (2009). Progress on the DUT project. GroundWork, 11(3), 15.

Naidoo, R. N., Gqaleni, N., Robins, T., Batterman, S., Gounden, Y., Jack, C., et al. (2007). The South Durban health study: Final project report. University of KwaZulu-Natal, Durban, South Africa.

O'Brien, F. (2009). In pursuit of African scholarship: Unpacking engagement. High Educ., 58, 29-39.

Pike, G. R., Kuh, G. D., \& McCormick, A. C. (2011). An investigation of the contingent relationships between learning community participation and student engagement. Res. High Educ., 53, 300-322. 
Singh, P. (2013). Environmental education: Enhancing learning and awareness through assessment. Syst. Pract. Action. Res., 26, 299-314.

Tanaka, K., \& Mooney, P. H. (2010). Public scholarship and community engagement in building community food security: The case of the University of Kentucky. Rural Sociology, 75(4), 560-583.

Thomson, A. M., Smith-Tolken, A. R., Naidoo, A. V., \& Bringle, R. G. (2011). Service learning and community engagement: A comparison of three national contexts. Voluntas, 22, 214-237.

Wallen, M. R., \& Pandit, A. S. (2009). Encouraging undergraduate engineering students towards civic engagement. European Journal of Engineering Education, 34(2), 141-148.

Zhao, C., \& Kuh, G. D. (2004). Learning communities and student engagement. Research in Higher Education, 45(2), $115-138$. 